\title{
Climatic Characteristics of Dust Storms in Jordan
}

\author{
Ali Ahmad Ghanem \\ Geography Department, The University of Jordan, Amman, Jordan \\ Email: Ali.Ghanem@ju.edu.jo
}

How to cite this paper: Ghanem, A. A (2020). Climatic Characteristics of Dust Storms in Jordan. American Journal of Climate Change, 9, 136-146. https://doi.org/10.4236/ajcc.2020.92010

Received: January 19, 2020

Accepted: June 6, 2020

Published: June 9, 2020

Copyright $\odot 2020$ by author(s) and Scientific Research Publishing Inc. This work is licensed under the Creative Commons Attribution International License (CC BY 4.0).

http://creativecommons.org/licenses/by/4.0/

(c) (i) Open Access

\begin{abstract}
This study is devoted to examine the climate characteristics of the Dust Storms (DS) with visibility $0-1 \mathrm{~km}$ that occurred in Jordan for the period 1988 to 2018. It is found that the DS varies temporally and spatially, as the largest number of DS occurred in 2003 (36 DS) and the lowest occurred in 1999 (one DS). The average was 17.22 DS with the coefficient of variation of $45 \%$, the DS durations ranged from 1 - 4 days, most of them occurred in spring (54.1\%) especially in April (22.2\%). The DS increased southward and eastward directions, they increased from 13 DS in Irbid in the north to 182 DS in Al-Jafr in the south and to 102 DS in Safawi in the east. The results showed positive relationships between wind speeds. There were negative relationships with relative humidity, pressure and rainfall, and there was no relationship between DS and the maximum temperature.
\end{abstract}

\section{Keywords}

Dust Storms, Temporal, Rainfall, Winds, Jordan

\section{Introduction}

Jordan is located in the Eastern Mediterranean region between $29.15^{\circ}-32.55^{\circ} \mathrm{N}$ and $35^{\circ}-39^{\circ} \mathrm{E}$, the Mediterranean climate prevails in the north-western parts of Jordan and the semi desert and dry desert climate prevail in the southern and eastern parts which make about $80 \%$ of Jordan area. Therefore, Jordan is heavily exposed to the occurrence of dust storms that occur when the wind speed increases enough to carry dust materials less than 20 microns transported by winds over great distances. The Sahara is a major source of dust from which it reaches the Eastern Mediterranean (Goudi \& Middleton, 2001; Morales, 1986). Dust storms usually occur between October and May. 
The dust storms are natural atmospheric phenomena that have negative effects as a result of dust spread, low visibility, accidents, and their impacts on human activities and health (Albugami et al., 2019; Khalil, 2008). Dust and sand affect agriculture by destroying crops and decreasing productivity (Alezawi, 2015; Salem, 2004; Alsaid, 2004). Dust storms have also an impact on reducing the amount of solar radiation and increasing the intensity of wind erosion which is an important factor causing desertification (Hamdi et al., 2013; Muhammed et al., 2015; Goudie, 1978; Wang et al., 2006).

Dust storms are often associated with low presser systems. Many dust storms occur in the eastern Mediterranean region at the front of the cold air fronts, or in the warm sector, where south to southwesterly winds prevail, and the storms begin to fade as the cold air front advances causing rainfalls that wash the atmosphere from dust (Brazel \& Nickling, 2007; Meddleton, 1986).

This research aims to study the climatic and statistical characteristics of dust storms and to show their temporal and spatial distribution and the impact of climate elements on them. Attention was limited to the dust storms in which visibility was $0-1 \mathrm{~km}$. The research is concerned with the study of dust storms, which were consisted of dust carried by the air to hundreds and thousands of kilometers in the atmosphere, and affect visibility which sometimes drops to zero km (Morales, 1986).

\section{Data}

Data was obtained for eight stations during the period 1988-2018 from the Jordanian Meteorological Department and the Ministry of Water. Daily data include visibility, maximum temperature, relative humidity, atmospheric pressure, wind speed and direction, and the amount of rainfall. The study stations were selected to provide their data during the whole study period and are distributed among the different geographical regions in Jordan. The stations of Amman Airport and Irbid are representing the central and north-west Region, Deir alla and Aqaba representing the Jordan Valley, and Al-Jafr, Ma'an, Mafraq and Safawi stations representing the Jordanian Badia (Figure 1).

\subsection{Methodology}

The research aims to study and understand the statistical characteristics related to dust storms in Jordan, and to clarify the impact of different climate elements and their relationship with the occurrence of dust storms. Dust storms with a visibility range $0-1 \mathrm{~km}$ were determined and each storm was adopted if such visibility was recorded at one or more stations. To achieve the objectives of the research, statistical methods were used to calculate averages, standard deviation and coefficient of variation to understand the monthly, seasonal and annual spatial variation of the dust storms in the eight studied stations. The logistic regression method was used to illustrate the relationship between climate elements and dust storms (Al-Saleh \& Al-Syriani, 2000). 


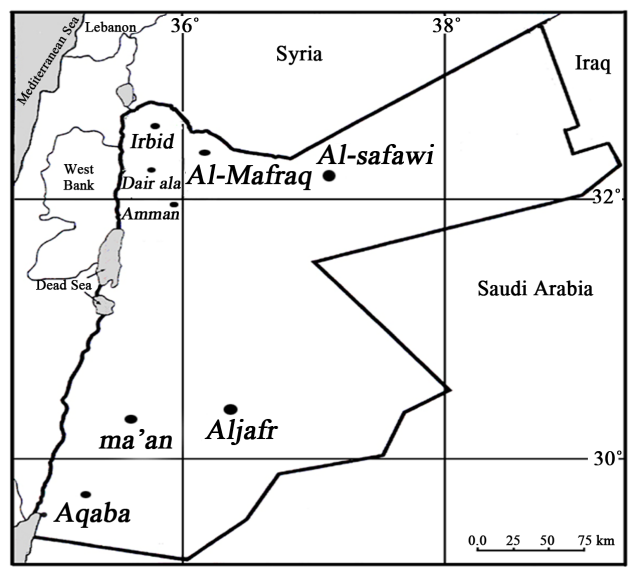

Figure 1. Station location.

\subsection{Visibility}

Visibility is an important element of dust storms for its negative effects. Visibility decreases as dust concentration increases in the atmosphere. The range of visibility in dust storms $0-1 \mathrm{~km}$ was divided into four groups as shown in Figure 2.

Group 1: includes very severe dust storms with visibility $0-0.2 \mathrm{~km}$, there were (146) storms (26.6\%), most of them (88 storms) occurred in Spring, and the least (15 storms) occurred in Summer. The occurrence of these storms was concentrated in the southern region of Jordan where 78 storms (53.4\%) recorded in Al-Jafr station.

Group 2: Includes severe dust storms, which visibility $0.3-0.5 \mathrm{~km}$, there were 79 storms (14.4\%) occurred, most of them (41 storms) occurred in Spring and the least (11 storms) occurred in Autumn. The storms of this group were concentrated in the desert as in the stations of Al-Jafr (20 storms), Safawi (16 storms) and Aqaba (13 storms).

Group 3: Includes moderate dust storms with visibility between $0.6-0.8 \mathrm{~km}$. This group represents the lowest number of storms, 38 storms (6.9\%) occurred during the study period, about (60.5\%) of them occurred in Spring, and the most frequent occurrence was at Amman airport (26.6\%), and the lowest occurrence was At Deir Ala and Irbid Stations with one storm in each.

Group 4: Includes light dust storms with visibility between $0.9-1 \mathrm{~km}$, and includes about 292 storms (52\%) of the total storms, most of them 145 storms (50.7\%) occurred in Spring season, most of which occurred in the desert region of Jordan: (82 storms) in Jafr, (65) in Aqaba and (53) in Safawi, the least in Der alla and Irbid stations (Figure 3).

\subsection{Dust Storm Duration}

The length of a dust storm means the duration (days) in which it continued to affect any area in Jordan, which ranged from one to four days. The length of dust storms in Jordan during the study period was divided into three categories as shown in Table 1. It was found that short-term storms, which lasted one day, are 


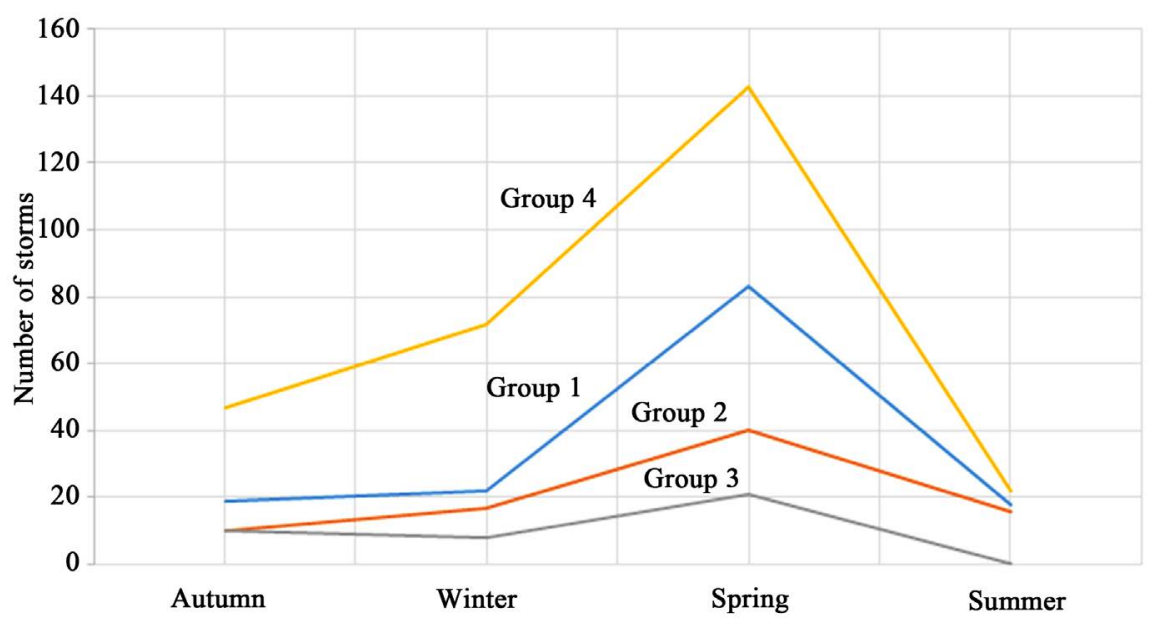

Figure 2. Seasonal distribution of visibility $/ \mathrm{km}$.

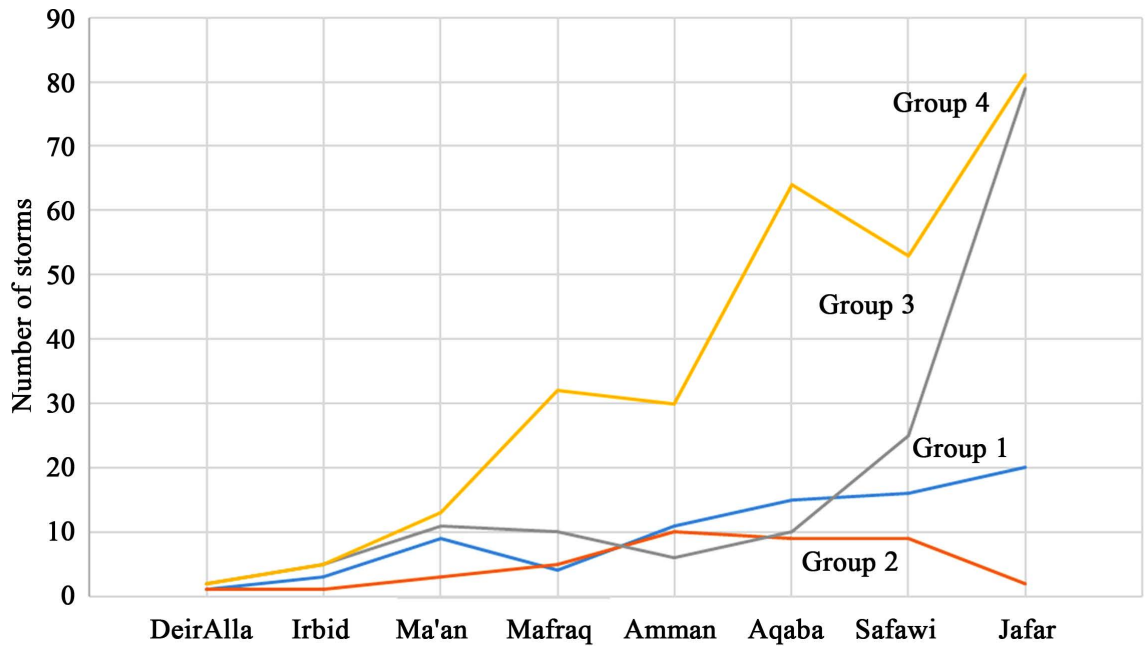

Figure 3. Spatial distribution of the dust storms according to visibility groups.

Table 1. Dust storm duration (days) at the study stations.

\begin{tabular}{cccccc}
\hline Station & Day & 2 Day & 3 Day & 4 Day & Total \\
\hline Irbid & 13 & 0 & 0 & 0 & 13 \\
Amman Airport & 33 & 9 & 2 & 0 & 44 \\
Dair alla & 7 & 2 & 0 & 0 & 9 \\
Aqaba & 71 & 9 & 2 & 0 & 82 \\
Ma'an & 32 & 2 & 0 & 0 & 34 \\
Al-Jafar & 131 & 16 & 5 & 1 & 153 \\
Al-Mafraq & 49 & 2 & 0 & 0 & 51 \\
Al-Safawi & 85 & 7 & 1 & 0 & 93 \\
\hline
\end{tabular}

the most common in all study stations and reached 421 storms (76.7\%) of the total. The rates vary between the stations, rising in Irbid station to reach $100 \%$, while the proportion decreases in the southern stations to $72 \%$ in Al-Jafr, $74.7 \%$ 
in Aqaba and $83.3 \%$ in Al-Safawi in the eastern region.

All dust storms that occurred in Irbid station was characterized by the fact that they were short-term of one day, due to high soil humidity and the spread of plants and trees which decrease blowing dust. The medium-length dust storms (two-day) accounted for 47 storms and were concentrated in the southern and eastern regions, most of them in Al-Jafr, Aqaba, Amman airports and Safawi. The long duration dust storms lasted for 3 - 4 days occurred only in Al-Jafr.

\section{Dust Distribution}

\subsection{Temporal Distribution of Dust Storms}

A dust storm was recorded in Jordan for the days the storm occurred regardless of its spatial extent. During the 31-year period, Jordan experienced 549 dust storms, with an average of 17.22 storms per year and a standard deviation of 7.86 storms, the coefficient of variation was $45 \%$. This indicates that there is a temporal variation in the occurrence of dust storms.

Jordan is exposed to dust storms in all months, but their distribution varies monthly, due to climatic factors affecting the storms. April was the most frequent month of dust storms in Jordan, with 122 storms (22.2\%) during the study period, while August was the least with only one storm (Table 2).

Table 2 shows significant variation and irregularity in the incidence of storms each month. The month of April was the least variable in the number of dust storms, with coefficient of variation of $78 \%$, which is the lowest among all months. About two-thirds of the dust storms occurred in February, March, April and May due to increasing instances of atmospheric instability and increasing incidence of depressions in the Mediterranean, the Red Sea and the Khamasines.

Table 2. Monthly distribution of dust storms.

\begin{tabular}{ccccc}
\hline Month & Number of storms & Average & Percentage \% & Standard deviation \\
\hline January & 29 & 0.9 & 5.3 & 1.8 \\
February & 60 & 1.9 & 10.9 & 2.6 \\
March & 89 & 2.9 & 16.2 & 3.6 \\
April & 122 & 3.9 & 22.2 & 3.4 \\
May & 86 & 2.8 & 15.7 & 2.4 \\
June & 74 & 0.8 & 4.4 & 1.7 \\
July & 24 & 0.8 & 4.4 & 2.5 \\
August & 1 & 0.03 & 0.2 & 0.2 \\
September & 13 & 0.4 & 2.4 & 1 \\
October & 36 & 1.2 & 6.6 & 1.4 \\
November & 34 & 1.1 & 6.2 & 1.7 \\
December & 31 & 1 & 5.5 & 1 \\
\hline & & & &
\end{tabular}


The number of dust storms varies considerably from season to season, with a seasonal average of 137.2 storms and a coefficient of variation of about $70 \%$, which indicates the great seasonal variation in the distribution of dust storms. Table 3 shows that most storms occur in Spring season and reached 297 storms (54.1\%), and most storms (76\%) occurred in winter and spring, the seasons in which most depressions and atmospheric instability occur (Al-Jumaily \& Ibrahimm, 2013).

The least dust storms occurred in Summer (49 storms) due to the rare occurrence of atmospheric instability and weak winds with an increase in the rate of calm conditions (Ghanem, 2006). The low number of dust storms in Winter compared to Spring due to the large amounts of rainfall in winter, rainfall reduces the incidence of dust storms. Autumn was the most regular season with a standard deviation of 2.1 storms, while Spring was the least regular with a standard deviation of 7.1 storms.

The number of dust storms varied from year to year. Figure 4 shows the annual fluctuation of the number of sand storms about the average, ranged between one storm in1999 to 36 storms in 2003. The annual variation of dust storms may be explained by the different impact of synoptic conditions associated with the occurrence of atmospheric depressions, and atmospheric instability (Sababha, 2005), leading to the conclusion that most storms in Jordan are more of external than domestic sources. So the eastern and southern winds are usually bringing dust from neighboring deserts.

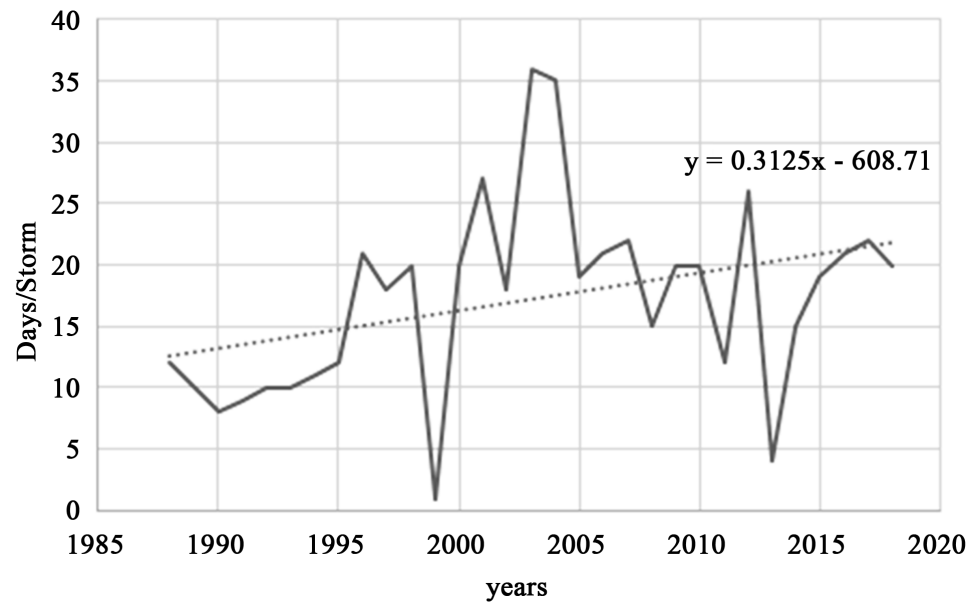

Figure 4. Annual distribution of dust storms.

Table 3. Seasonal distribution of dust storms.

\begin{tabular}{ccccc}
\hline Season & Number & Average & Percentage \% & Standard deviation \\
\hline Autumn & 83 & 2.7 & 15.1 & 2.1 \\
Winter & 120 & 3.9 & 21.9 & 3.4 \\
Spring & 297 & 9.5 & 54.1 & 7.1 \\
Summer & 49 & 1.6 & 8.9 & 4.1 \\
\hline
\end{tabular}




\subsection{Spatial Variation}

Analysis of dust storm data shows variations in the number of storms in the study stations. Table 4 shows that the largest number of storms were occurred in $\mathrm{Al}$ Jafr (in southern Jordan), and the lowest in Irbid (in northern Jordan). About $85.2 \%$ of the storms occurred in the Jordanian Badia (Aqaba, Ma'an, Al-Jafr, Mafraq and Safawi). It is noticeable from the table that the number of dust storms increased eastward and southward. The number of storms increased eastward from 13 storms in Irbid, 53 storms in Mafraq and 102 storms in Safawi. The number of storms is also increased southward comparing Al-Jafr and Aqaba to Irbid and Deir Alla.

About 13 storms (8\%) had affected most parts of the country including the humid northwestern region, while the other storms had different area cover; the western highlands were free of dust storms. The increase in storms in the southern and eastern regions is due to factors that encourage dust storms development: such as drought, soil disintegration, poor vegetation cover, topography, and rare rainfall. This is in contrast to conditions in the northern and mountainous areas of Jordan, where there is more rainfall and vegetation cover, which reduce wind speed and increase soil cohesion. Rainfall in mountainous and northwestern regions is more frequent, as rainfall is an important factor for preventing or ending dust storms. This applies to the Deir Alla station, with the lowest number of (11 storms), which is located in the northern Jordan Valley between longitudinal mountain ranges from north to south that limits the ability of the wind to penetrate and carry dust.

\section{Climate Elements Effects}

Humidity (RH) and the occurrence of dust storms, the lower the relative humidity the greater the probability of dust storms. the increase in relative humidity may lead to low wind ability to provoke and carry dust and improving visibility, it was recorded in Irbid storm on 2/5/2008 when the humidity was 33\% and visibility is $1 \mathrm{~km}$, on the next day the relative humidity increased to $71 \%$ and visibility improved to eight kilometers. In Summer and Autumn, the analysis did not

Table 4. Spatial distribution of dust storms in Jordan.

\begin{tabular}{ccccccccc}
\hline \multirow{2}{*}{ Station } & \multicolumn{2}{c}{ Summer } & \multicolumn{2}{c}{ Spring } & \multicolumn{2}{c}{ Winter } & \multicolumn{2}{c}{ Autumn } \\
\cline { 2 - 8 } & $\%$ & Num & $\%$ & Num & $\%$ & Num & $\%$ & Num \\
\hline Irbid & 0 & 0 & 69.2 & 9 & 15.4 & 7 & 15.4 & 2 \\
Amman Airport & 1.8 & 1 & 43.8 & 25 & 31.6 & 18 & 22.8 & 13 \\
Dair Ala & 0 & 0 & 45.5 & 5 & 45.5 & 5 & 9 & 1 \\
Aqaba airport & 9.5 & 9 & 68.4 & 65 & 16.8 & 16 & 5.3 & 5 \\
Ma'an & 5.6 & 2 & 47.2 & 17 & 22.2 & 8 & 25 & 9 \\
Al-Jafar & 15.4 & 28 & 50.6 & 92 & 22.5 & 41 & 11.5 & 21 \\
Al-Mafraq & 7.5 & 4 & 52.8 & 28 & 18.9 & 10 & 20.8 & 21 \\
Al-Safawi & 4.9 & 5 & 54.9 & 56 & 19.6 & 20 & 20.6 & 21 \\
\hline
\end{tabular}


show statistical significant relationship between the relative humidity and the probability of dust storms (Table 5).

The analysis of atmospheric pressure (AP) showed seasonal variations with limited affect on dust storms in Winter and Spring, with a coefficient of interpretation of $2.8 \%$ in Winter and $1.4 \%$ in Spring. There was an inverse relationship between the probability of the occurrence of dust storms and atmospheric pressure. The higher the value of atmospheric pressure the lower the probability of dust storms in Winter and Spring. The deep low pressure systems lead to increase the pressure gradient causing stronger winds that capable of causing dust storms and low visibility, as recorded in Safawi storm on 22/2/2004 when the visibility was zero due to the presence of a deep low and severe northern winds with a speed of 78 knots. The relationships between the probability of dust storms and the wind speed in Spring and Winter were due to the high instability of the weather, the higher the wind speed, the more likely the occurrence of dust storms in these two seasons (Dehghanpour et al., 2014; Mahrt, 2010).

Analysis showed statistical relationships between the atmospheric pressure and the probability of dust storms in Summer and Autumn. The Summer and Autumn wind speeds affect the occurrence of dust storms, where the wind speed contributed to explain about $21.4 \%$ of the of dust storms in Winter, $15.6 \%$ in Spring and $12.6 \%$ in Autumn (Table 6).

Table 5. Seasonal logistic regression analysis, showing the relationship of dust storms with maximum temperature $(\mathrm{T})$ relative humidity $(\mathrm{RH})$ Atmospheric pressure (AP) and wind speed (S).

\begin{tabular}{|c|c|c|c|c|c|c|c|}
\hline Season & Variables & $\mathrm{R} 2$ & significance & D.F & Wald index & Standard error & Regression \\
\hline \multirow{4}{*}{ Autumn } & $\mathrm{H}$ & - & - & - & - & - & - \\
\hline & RH & - & - & - & - & - & - \\
\hline & AP & - & - & - & - & - & - \\
\hline & S & 0.126 & 0.001 & 1 & 10.82 & -0.61 & -0.2 \\
\hline \multirow{4}{*}{ Winter } & $\mathrm{H}$ & - & - & - & - & - & - \\
\hline & $\mathrm{RH}$ & 0.187 & 0.002 & 1 & 9.4 & 0.013 & -0.04 \\
\hline & $\mathrm{AP}$ & 0.28 & 0.027 & 1 & 5.7 & 0.045 & -0.11 \\
\hline & S & 0.214 & - & 1 & 27.7 & 0.019 & 0.1 \\
\hline \multirow{4}{*}{ Spring } & $\mathrm{H}$ & - & - & - & - & - & - \\
\hline & $\mathrm{RH}$ & 0.89 & 0.019 & 1 & 5.47 & 0.008 & 0.018 \\
\hline & $\mathrm{AP}$ & 0.14 & - & 1 & 28.1 & 0.035 & -0.18 \\
\hline & S & 0.156 & - & 1 & 30.4 & 0.011 & 0.062 \\
\hline \multirow{4}{*}{ Summer } & $\mathrm{H}$ & - & - & - & - & - & - \\
\hline & $\mathrm{RH}$ & - & - & - & - & - & - \\
\hline & AP & - & - & - & - & - & - \\
\hline & S & - & - & - & - & - & - \\
\hline
\end{tabular}


Table 6. Spatial distribution of dust storms followed by rain $(\mathrm{mm})$ in study stations.

\begin{tabular}{cccc}
\hline \multirow{2}{*}{ Station } & Number of storms & \multicolumn{2}{c}{ Number of storms with rain } \\
\cline { 3 - 4 } & 13 & Num & $\%$ \\
\hline Irbid & 57 & 12 & 30.8 \\
Amman & 11 & 3 & 21 \\
Dair Alla & 95 & 3 & 27.3 \\
Aqaba & 36 & 3 & 3.2 \\
Ma'an & 182 & 12 & 8.3 \\
Al-Jafar & 53 & 12 & 6.6 \\
Al-Mafraq & 102 & 11 & 22.6 \\
Al-Safawi & 549 & 60 & 10.8 \\
Total & & & 10.9 \\
\hline
\end{tabular}

In Autumn, the relationship between dust storms and wind speed was inverse, the lower the wind speed the greater the probability of dust storms due to frequent instances of atmospheric instability, as the dust storm recorded in Safawi on 16/10/2009 where the wind speed was 13 knots. In Summer, the analysis did not show statistically significant of wind speed, and therefore showed no correlation between wind speed and probability of dust storms, the prevalence of calm conditions affects the relationship (Al-Jumaily \& Ibrahimm, 2013).

Therefore, the wind speed wasn't a distinctive limit for the occurrence or non-occurrence of a dust storm. Dust storms can be associated with varying wind speeds. The wind speed may reach 52 knots without dust storm events, and the visibility increases to ten kilometers, this was in the event observed at Ma'an station on $30 / 11 / 2011$. While a dust storm with low visibility of $0.2 \mathrm{~km}$ occurred with lower wind speed of 9 knots, as observed in Mafraq on 14/10/2004. This is due to the presence of variables other than wind contributing to the occurrence of the dust storm.

On the other hand, dust storms can have the same intensity and the same range of visibility, with different wind speed, as of the storm recorded in of Al-Jafr on 23/3/1996 and 5/12/2015, the visibility in both was zero, while the wind speed in the first storm was (7) knots and in the second (44) knots. The same wind speed in dust storms also produced different visibility, as in the two storms that were observed at Aqaba Station on 17/7/2000 and 3/3/2001, where they had a similar wind speed of (31) knots and different visibilities, it was $1 \mathrm{~km}$ during the first storm and $0.1 \mathrm{~km}$ in the second storm.

The dust storms occurred with the southern, eastern, and southeastern winds coming from the desert areas (the Sinai desert as an extension of the Sahara and Arabian Desert) which arrive to Jordan loaded with dust from those deserts. Dust storms rarely occurred with northern or western humid winds.

\section{Rainfall}

Rainfall usually ended the dust storm that had already formed or prevented a 
new storm by increasing soil moisture. Winter season was the most seasons in which rainfall occurred after the occurrence of dust storms and led to the end of those storms. Most dust storms, which ended by rain were concentrated in Winter (27 storms 45\%), Spring (21 storms 35\%) and in Autumn (12 storms $20 \%)$.

There was also a discrepancy between the stations in the frequency of rainfall that followed the dust storms and caused the end of it, from the total frequency of storms in each station, the most frequent was in the northern region with about $30.7 \%$ in Irbid, 27.3\% in Deir Alla, 22.6\% at Mafraq and 21\% at Amman Airport. The northern region is more affected by the cold air fronts and depressions coming across the eastern Mediterranean (Table 6). The frequency of rainfall after dust storms decreased in southern region to $6.6 \%$ in Jafer and 3.2\% in Aqaba due to their dry climate.

\section{Conclusion}

Jordan is under weather and climate fluctuation, therefore exposed to temporal (monthly, seasonal and annual) and spatial dust storm variation. The occurrence of dust storms in Jordan is concentrated in four months: February, March, April and May, with increasing frequency and intensity southward and eastward. The majority of dust storms occurred in the southern and eastern regions due to lack of soil moisture, lack of rainfall, and poor vegetation cover. They are less frequent in the mountainous and northern regions because of the high rainfall amounts and humidity, in addition to the vegetation cover of forests and plantations.

There are many factors affecting the formation of dust storms. Climate elements (humidity, temperature, rainfall, wind speed) affected the formation of dust storms. All elements interact to make the conditions suitable to dust storm formation, which can develop under different conditions in all months.

Global warming with the increase of mean temperature (dryness) and the decrease of rainfall amounts in Jordan may explain the insignificant increase of dust storms especially in the last two decades (Ghanem, 2013). Global warming may become certain if dust storms duration and intensity increase during the coming years.

\section{Conflicts of Interest}

The authors declare no conflicts of interest regarding the publication of this paper.

\section{References}

Albugami, S., Palmer, S., Cinnamon, J., \& Meersmans, J. (2019). Spatial and Temporal Variation in the Incidence of Dust Storms in Saudi Arabia Revealed in Situ Observations. Geosciences, 9, 162. https://doi.org/10.3390/geosciences9040162

Alezawi, F. (2015). Climate Change and Dust Storms in Iraq. Journal of Economic Sciences, 21, 327-347. 
Al-Jumaily, K., \& Ibrahimm, M. (2013). Analysis of Synoptic Situation for Dust Storms in Iraq. International Journal of Energy and Environment, 4, 851-858.

Alsaid, A. (2004). Climate and Agriculture: A Study in Applied Climatic Geography of the Nile Delta Environment. Alexandria: Faculty of Arts, Alexandria University.

Al-Saleh, N. A., \& Al-Syriani, M. (2000). Quantitative and Statistical Geography: Fundamentals and Applications of Modern Computational Methods (2nd ed.). Riyadh: Obeikan.

Brazel, A. J., \& Nickling, W. K. (2007). The Relationship of Weather Types to Dust Storm Generation in Arizona (1965-1980). International Journal of Climatology, 6, 255-275. https://doi.org/10.1002/joc.3370060303

Dehghanpour, A. R., Halabian , A. H., \& Fallahpour, M. (2014). Impact of Wind Direction and Speed on Dusty Days. International Journal of Advanced Biological and Biomedical Research, 2, 1742-1749.

Ghanem, A. (2006). Spatial and Temporal Variation of Wind Speed in Jordan. Journal of Social Sciences/Kuwait University, 34, 111-140.

Ghanem, A. (2013). Trends and Early Prediction of Rainfall in Jordan. American Journal of Climate Change, 2, 203-208. https://doi.org/10.4236/ajcc.2013.23021

Goudi, A. S., \& Middleton, N. J. (2001). Sahara Dust Storms Nature and Consequences. Earth Science Reviews, 56, 179-204. https://doi.org/10.1016/S0012-8252(01)00067-8

Goudie, A. S. (1978). Dust Storm and Geomorphologic Implications. Journal of Arid Environments, 1, 291-310. https://doi.org/10.1016/S0140-1963(18)31712-9

Hamdi, M., Kavianpour, M., \& Shao, Y. (2013). Synoptic Analysis of Dust Storms in the Middle East. Asia-Pacific Journal of the Atmospheric Sciences, 49, 279-286.

https://doi.org/10.1007/s13143-013-0027-9

Khalil, Y. M. (2008). Dust Storms in Jordan during the Years 1975-2005. Unpublished Ph.D. Dissertation, Amman: University of Jordan.

Mahrt, L. (2010). Surface Wind Direction Variability. Journal of Applied Meteorology and Climatology, 50, 144-152. https://doi.org/10.1175/2010JAMC2560.1

Meddleton, N. J. (1986). Dust Storms in the Middle East. Journal of Arid Environment, 10, 83-96. https://doi.org/10.1016/S0140-1963(18)31249-7

Morales, C. (1986). The Airborne Transport of Sahara Dust: A Review. Stockholm: Department of Meteorology, University of Stockholm.

Muhammed, S., Al Fatla, N. M., \& Abdul Wahab, S. A. (2015). Analyzing the Synoptic Patterns Associated to Dust Events over West Asia during Summer Months-Case Studies. Journal of Applied Physics, 7, 53-66.

Sababha, N. (2005). Air Instability in Jordan (1990-2003). Unpublished Master Thesis, Amman: University of Jordan.

Salem, T. Z. (2004). Sand and Dust Storms and Their Impact on Agriculture in Jizan Region, Saudi Arabia. Arab Geographical Journal, 36, 1-34.

Wang, X. M., Chen, F., \& Dong, Z. (2006). The Relative Role of Climatic and Human Factors in Desertification in Semiarid China. Global Environmental Change, 16, 48-57 https://doi.org/10.1016/j.gloenvcha.2005.06.006 